\title{
Advance Parties: The deer industry trial of farmer groups to lead practice change for improved profit
}

\author{
I. MOFFAT \\ P2P Manager, Deer Industry New Zealand \\ PO Box 10702, Wellington, New Zealand \\ Innes.moffat@deernz.org
}

\begin{abstract}
Deer Industry New Zealand established Advance Parties to improve profitability among New Zealand deer farmers. The number of deer farmed in New Zealand has fallen in the past decade and new ways of doing things are needed to ensure farmers are confident in the animal as a profitable part of the pastoral agricultural mix. Advance Parties are a farmer-centric means of encouraging adoption of new practices to improve the profitability of farming deer. Advance Parties are small groups of like-minded farmers focussed on helping each other implement, record and observe changes on their properties, with external assistance when needed. The results of these changes will be disseminated to the wider deer farming community. Deer Industry New Zealand is running 15 Advance Parties as at November 2015, with the aim of running 30 on an ongoing basis. This would involve approximately 300 deer farms.
\end{abstract}

Keywords: Deer Industry New Zealand, Passion2Profit, deer farming practice change

\section{Key messages}

- Advance Parties are one means of encouraging adoption of new practices to improve profit from deer farming

- The trial phase is testing the best means of encouraging farmer-led behaviour change

- Initial results indicate individuals will adopt new management practices when motivated in a supportive environment.

\section{Background}

The New Zealand deer industry requires a transformational change to improve confidence that profitability is at least competitive with alternative land uses and thereby retain critical mass. In recent years, the risks inherent in a reliance on a seasonal sales period in a market with a common currency have materialised, with European economic and currency weakness dragging returns to most deer farmers below those of alternative land uses. The national deer herd has fallen from its peak of 1.7 million in the early 2000s to under 1 million in 2015. Without change, New Zealand will miss the opportunity to derive full market value from farmed venison products.

A minority of leading farmers have shown that integrating the best scientific knowledge on deer feeding, animal health, and genetics into farm systems does result in delivery of sufficient returns from deer farming. Those technologies have not, however, been packaged into solutions that the majority of farmers choose to use or are capable of deploying.

New Zealand's five major venison marketing companies and the New Zealand Deer Farmers' Association have agreed to a programme of work that endeavours to create transformational change in the New Zealand venison industry, and will be supported by their industry good organisation, Deer Industry New Zealand (DINZ), to deliver it. This programme has been named Passion2Profit (P2P). Central to the P2P is the Advance Party project - a means of allowing deer farmers to gain confidence, skills and motivation to make changes to the management of deer to improve the profitability of their deer farming operations.

\section{Passion2Profit}

The P2P is made up of two groups of interlinked projects:

1. Marketing premium venison

This project aims to increase the amount of venison sold year round in chilled form at higher prices, through collaborative branding and positioning of New Zealand venison in new markets or new market niches.

2. Market led production

This project aims to develop the systems that will "power up" farmers' ability to respond to current and future market value drivers.

Project 2 will apply a two-pronged approach - firstly, packaging the enabling farming technologies into solutions convenient for farmers, and secondly, by creating new, innovative opportunities to engage with farmers to deliver those solutions. In the first instance the technology packaging will involve systematisation of feeding, genetics and animal health knowledge, and the creation of an industry champion for each. In the second instance P2P will create new, in-person, on-line and correspondence mechanisms for engagement with 
farmers to drive adoption solutions.

\section{Barriers to adoption}

Deer Industry New Zealand commissioned a report into deer farmers' attitude to change (CINTA 2011) that highlighted that the four main incentives to change were improving the productivity, profitability and sustainability of farmers and improving animal welfare. What have been missing to date are consistent commercial signals to describe and encourage the required change and the structures to break down the barriers of change and enhance the influencers of change.

A recent notable enabler of producer change is individual electronic identification of deer. However, producers need to be able and willing to collect and analyse these data to know how productive they are, and then know where to get the best information to make the right management decisions.

\section{'Practice Change'}

Achieving 'Practice Change' is a critical element of the $\mathrm{P} 2 \mathrm{P}$ and one which will to a large extent determine whether the P2P is successful or not. Assuming that knowledge of how to implement farming systems that deliver market requirements exists, the critical challenge becomes engagement with farmers to drive adoption of those systems. The term 'Practice Change' is used to convey an approach to change which is relational and based on personal attitude to change as opposed to 'command and control' or 'transactional'.

Personal attitude to change is based on a number of factors, including:

- Motivation, e.g. profit, altruism, peer recognition, legacy, competing priorities

- Confidence, e.g. self-belief, past success or failures, peer / advisor / family support

- Ability, e.g. skills, knowledge, experience, debt levels.

Tactical practice change initiatives are operational, on-the-ground tools, which drive behaviour change. The Deer Industry has an array of traditional practice change engagement strategies in place - such as Focus Farms - which have had success, but with limited reach. P2P will develop and trial some innovative new practice change engagement strategies.

A central means of encouraging the adoption of the new technology and implementing change in the P2P programme is the Advance Party project.

\section{Advance Party}

An Advance Party (AP) is a well-supported group of motivated deer farmers who identify opportunities and implement changes to lift profit on their individual farms. There will be some element of farming practice that is common to all AP.
AP's facilitate change by group learning - trialling different changes as part of a supportive group to see their effect on profit, and sharing the results with the wider deer farming community to encourage wider adoption of successful changes. Figure 1 shows the process in a simplified way.

Each AP is comprised of about 10 farming businesses. It is important to note that all key decision makers from each farming business, especially the spouses in farming families, are encouraged to participate in the AP.

Without confidence, motivation and knowledge, producers are reluctant to change. AP's provide a supportive environment that encourages producers to learn from others' experiences and implement practice changes that will improve their deer farming skills and profitability. The results of these farmer-led changes will be disseminated through the wider deer farming community, using traditional engagement approaches, helping to lift the prevalence of the most effective management techniques until they become common practice.

An AP is not a traditional discussion group. Group members must be committed to shared personal and farm business development, sharing their data, methods, plans, results, problems and successes. They are not for the group alone, but are a means to test and refine opportunities for profit, and to demonstrate those methods (and their limitations) to the wider deer farming community. AP's will be supported by DINZ and run collaboratively by a chair nominated from within the group members and an independent facilitator. Their roles are defined below:

\section{The DINZ role}

The role of DINZ is to provide physical resources and practical support for the management of AP's. DINZ project manager(s) will provide oversight and monitoring of the Advance Party initiative. They are the first point of contact for the AP facilitators and chairs who are seeking guidance.

\section{The Chair's role}

Each AP will appoint a chair from within their members to lead their group. The chair will lead meetings and work with the facilitator to organise meetings and resources. The chair will also be an active member of the AP who should be working to implement improvements on their own farm.

\section{The Facilitator's role}

The facilitator's role is to coordinate the group by following a well-structured process and to instil confidence in the members so that they, in time, can run their own meetings. A facilitator is not to advise a group 
How Advance Parties Work

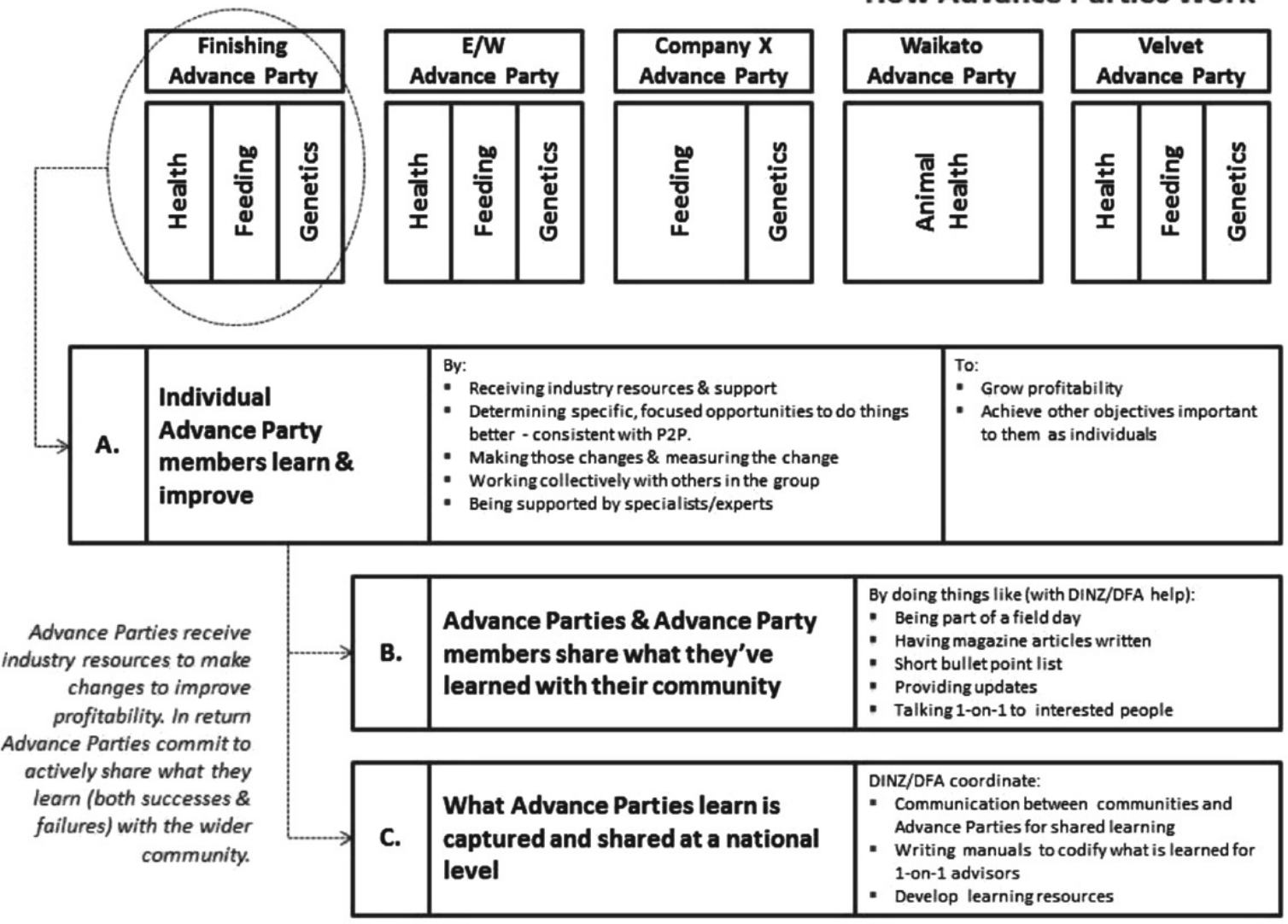

Figure 1 Simplified Advance Party (AP) process.

where their focus should be, or to give direct answers to questions, but rather to create an atmosphere where the group members collectively develop and brainstorm potential issues and solutions themselves to assist other group members.

All successful rural programmes have a key individual who maintains the drive or focus within any group. The facilitator is there to act as this motivator for the group.

The facilitator will keep a record of key objectives, issues and statements made within the AP day to ensure that discussions can be tailored around topics that are relevant to the member(s) in question. This is also kept as a record of the AP day at DINZ and circulated to group members post-meeting.

\section{Recruitment and early outcomes}

DINZ has a goal of operating up to 30 AP's at any one time. DINZ recognises the formidable financial and personnel requirements to achieve this goal. Once this trial phase is completed the AP programme will become part of the Primary Growth Partnership co-funded P2P programme. DINZ has used the NZ Deer Farmers Association branch network to form the first round of AP's.
The first advance party was formed in early 2014 in the MacKenzie Country. Managers and/or owners of six properties were invited to attend early meetings by a leading farmer from the district. A common characteristic of all these properties was that deer comprised the $3^{\text {rd }}$ class of livestock on these extensive high country runs, often playing third fiddle to merinos and cattle.

Only one of the group weighed their deer, and no one undertook proper body condition scoring, or collected production data to the extent prescribed as necessary to record productivity metrics (e.g. kg venison produced per kg live hind mated). Most were questioning the role deer had on their properties.

After 2 years deer numbers are expanding on the MacKenzie Country properties. All the AP members now have weigh scales and are monitoring deer performance, and are excited about the potential for deer on their properties.

The members of the group observed that the biggest benefit they got from involvement in the AP was that during the 2014 drought they were able to discuss their personal situation with others in a supportive atmosphere, which helped them take the steps needed to manage through a stressful time. A 
similar transformation in attitude toward deer and farm management has occurred in other Advance Party groups.

\section{Monitoring - change from "data driven" to "docu- menting change"}

In their initial form, APs were to be project focussed and data driven. Individual farmers were to regularly collect data on their operations and provide updates to monitor progress against national targets, and comparisons could be made across groups to observe the rate of change.

The reality, however, was somewhat different. Differences in farm management systems and recording made meaningful between farm comparisons difficult, and DINZ observed a resistance to data collection and production recording among deer farmers. In practice, few of the deer farmers in Advance Parties undertook performance monitoring of venison production.

An initial report was undertaken by AgResearch (Peoples 2014) on the attitudes to change among AP participants. Twenty five telephone interviews were completed over 2 months in early 2014. Broadly, the report indicated that farmers who had recently joined APs were keen to advance the production and profitability of their deer farming operations but were not assessed as innovative or industry leaders, therefore, were less likely to change than producers who were rated as 'innovators'.

Monitoring of attitudes to change among the AP participants will continue with an assessment due in 2016 to observe attitude change as a result of inclusion in an AP.

The lack of comparable farm data among the early AP participants means the collection of evidence of change currently focusses on documented change. AP facilitators are tasked with collecting records of the actions that individual farmers take and what changes they make. Facilitators are asked to record: What was the initial issue/opportunity, what did the farmers do, what was the outcome and would they do it again?

This process of documenting change, taken from the farmer's perspective, is expected to provide a better record of the actions and provide 'real world' experiences of producers which farmers may find more relevant than a data-centric report.

The common elements of successful AP's to date have included:

1. Strong leader in the group. This could be the facilitator, the chair or one of the farmers. A motivator to encourage involvement and participation is the most important factor contributing to a vibrant group.

2. An open and trusting environment. Where people will offer opinions, make suggestions and ask questions without fearing a negative response from individuals within the group.

3. Some information for action. Groups are initially reluctant to collect and analyse data; resisting the demand to collect numbers for the sake of it. But, once the group settle upon making changes that can be measured, the conversations, and the sense of friendly competition for everyone's benefit, raise up a notch. Examples of this include:

- Foetal scanning - to allow comparison of pregnancy rates and compare management practices that arrive at higher rates

- Feed budgeting - not new, but not often undertaken on winter crops in some areas that have traditionally relied on grass wintering systems

- Weighing finishing animals. Provides group members with points of reference to consider their own operations and discuss actions that can be taken to improve profit.

Some groups are taking longer to get established, and the factors behind this could be:

1. Inclusion of a divisive personality in the group.

2. Lack of a leader in the group who is able to establish an initial direction for the group.

3. A "wait and see what this does for us" attitude. It is a truism that you will only get out what you put in, and Advance Party participants must be prepared to expend some time and energy on thinking about their opportunities at the outset for the APs to be a success.

\section{Next steps}

DINZ needs to understand what will help the APs evolve so they remain relevant. At the outset it was planned that an AP should have a finite life. If project based it should have a defined end point so that members knew that they were working toward a goal. The APs have evolved since their inception and it was found that it is only after the group has been meeting for at least a year that the members move on from the easy wins to the more strategic questions about farm management monitoring. The first round of visits often identify the obvious improvements that farmers probably know they should do, but need the motivation of some scrutiny of their peers to make the obvious changes that will improve efficiency. In many instances we are observing these obvious fixes occupy farmers' pragmatic problem solving approach, before the members move on to consider broader issues of farm systems analysis and management for group action.

Examples of the day to day fixes are:

- Application of nitrogen on hill country

- Extension of reticulated water supply

- Better netting on fences to prevent fawn deaths.

Examples of more strategic projects that whole groups have moved on to include:

- Leptospirosis monitoring and management 
- Group winter feed options and budgeting

- Appropriate financial analysis of deer performance.

\section{Conclusions}

The AP's are proving to be popular with the participants and are resulting in changes being made on individual properties. The benefits of belonging to an AP have been improved animal performance, increased confidence among deer farmers to tackle changes and improved social interaction between members. Advance Parties need a strong central leader, and a genuine commitment to participate among the members to be successful. The role of the facilitator is important to the functioning of the group, they must allow the participants to own the decisions being made. Deer Industry New Zealand looks forward to expanding the number of AP's being operated to reach a goal of 30 operational AP's at any one time.

\section{ACKNOWLEDGEMENT}

The author is thankful for the support from the Ministry for Primary Industries Sustainable Farming Fund for co-funding the trial phase of this project.

\section{REFERENCES}

Hudson, F.; Hawksley, R. 2012. Deer Industry New Zealand Achieving Practice Change. Report prepared for Deer Industry New Zealand, January 2012. Cinta Research.

Peoples, S. 2014. Advanced Parties Practice Change Project Report. Report Prepared For Deer Industry New Zealand. 
